\title{
Ingestion of the soluble dietary fibre, polydextrose, increases calcium absorption and bone mineralization in normal and total-gastrectomized rats
}

\author{
Hiroshi Hara*, Takuya Suzuki and Yoritaka Aoyama \\ Division of Applied Bioscience, Graduate School of Agriculture, Hokkaido University, Sapporo 060-8589, Japan
}

(Received 20 September 1999 - Revised 22 March 2000 - Accepted 27 March 2000)

\begin{abstract}
We previously demonstrated that feeding a highly fermentable and water-soluble dietary fibre, guar-gum hydrolysate (GGH) increased intestinal absorption of insoluble Ca salts in totalgastrectomized rats. In the present study, we examined the effects of feeding a less fermentable and water-soluble fibre, polydextrose (PD), on $\mathrm{Ca}$ absorption and bone mineralization in the normal and total-gastrectomized rats in comparison with the effects of GGH. Apparent $\mathrm{Ca}$ absorption was severely lowered by gastrectomy, and PD feeding ( $50 \mathrm{~g} / \mathrm{kg}$ diet $)$ partially restored the reduction of $\mathrm{Ca}$ absorption similarly to GGH feeding ( $50 \mathrm{~g} / \mathrm{kg}$ diet $)$. PD feeding also increased the $\mathrm{Ca}$ absorption in normal rats, but not GGH feeding. Femur Ca concentration was reduced with gastrectomy. Feeding PD for $21 \mathrm{~d}$ increased the bone Ca concentration in both normal and gastrectomized rats, but GGH feeding did not. In rats fed $\mathrm{PD}, \mathrm{pH}$ of the caecal contents was lower than in rats fed fibre-free and GGH diets; however, soluble Ca concentration in the caecal contents was not different between the diet groups. Short-chain fatty acid concentrations were much lower in the PD groups than in the GGH groups. We also examined in vitro $\mathrm{Ca}$ absorption by using everted sacs of the small intestine. Addition of $\mathrm{PD}$ to the serosal medium of the ileal sacs increased Ca absorption, but addition of GGH did not. These results suggest that the small intestine rather than the large intestine is responsible for the increase in $\mathrm{Ca}$ absorption in rats fed PD, and suggests that the mechanism for the increase by PD may be different from that by GGH.
\end{abstract}

Calcium absorption: Bone mineralization: Polydextrose: Dietary fibre

It is known that osteopenia is induced after gastric resection in patients (Koga et al. 1979; Nilas et al. 1985). Absence of gastric acid after this operation may impair insoluble $\mathrm{Ca}$ absorption because gastric acid is the most important factor for solubilization of insoluble Ca salts. We have previously shown that total gastrectomy markedly decreased insoluble $\mathrm{Ca}$ absorption and bone $\mathrm{Ca}$ in rats (Ohta et al. 1998). The reduction of the $\mathrm{Ca}$ absorption after gastrectomy was partially restored by feeding a highly fermentable, low viscosity dietary fibre, namely guar-gum hydrolysate (GGH; Takahashi et al. 1994), and we suggested that fermentation in the large intestine be involved in the restoration of $\mathrm{Ca}$ absorption (Hara et al. 1999). We also demonstrated that GGH feeding ameliorated the reduction of $\mathrm{Ca}$ absorption by partial nephrectomy in rats, and that the large intestine is fully responsible for the amelioration of the $\mathrm{Ca}$ absorption impaired by renal failure (Hara et al.
1996). The large intestine has high capacity for $\mathrm{Ca}$ absorption (Karbach \& Feldmeier 1993; Ohta et al. 1997), and solubilization of Ca salts by acids generated through microbial fermentation in the large intestine has been proposed as the mechanism responsible for the increase in $\mathrm{Ca}$ absorption observed following ingestion of highly fermentable, indigestible materials (Younes et al. 1996). However, some food saccharides are known to enhance the small intestinal absorption of Ca (Armbrecht \& Wasserman 1976; Goda et al. 1993; Suzuki et al. 1998). The mechanisms for the beneficial effects of the indigestible saccharides are not fully determined.

The aim of the present study was to examine effects of feeding polydextrose (PD) on $\mathrm{Ca}$ absorption and bone mineralization of normal and gastrectomized rats in comparison with those of feeding GGH. PD is a less fermentable dietary fibre with a low viscosity, and is a

\footnotetext{
Abbreviations: GGH, guar-gum hydrolysate; PD, polydextrose.

* Corresponding author: Dr Hiroshi Hara, fax +81 117062504 or +81 11716 0879, email hara@chem.agr.hokudai.ac.jp
} 
widely distributed dietary fibre source. Some studies on the physiological effects of PD showed that the soluble fibre retarded lipid transport into lymph (Ogata et al. 1997), but did not influence glucose absorption (Bamba et al. 1993). The effects of PD on mineral absorption have not been evaluated.

\section{Experimental methods}

\section{Animals and diets}

Rats used in the experiments were housed individually in stainless-steel cages with mesh bottoms. The cages were placed in a room with controlled temperature $\left(22-24^{\circ} \mathrm{C}\right)$, relative humidity (40-60\%) and lighting (lights on 08.0020.00 hours).

This study was approved by the Hokkaido University Animal Committee, and animals were maintained in accordance with the Hokkaido University guidelines for the care and use of laboratory animals.

\section{Apparent absorption of calcium in normal and gastrectomized rats (Experiment 1)}

Male Sprague-Dawley rats (Japan SLC, Hamamatsu, Japan), weighing about $100 \mathrm{~g}$ (5-weeks-old), were given free access to deionized water and the semi-purified stock diet shown in Table 1 for an acclimatization period of 6$8 \mathrm{~d}$, and were divided into two groups in Experiment 1 . Rats in one group ( $n$ 27) were subjected to total gastrectomy with Roux-en-Y reconstruction (Lambert,

Table 1. Composition ( $\mathrm{g} / \mathrm{kg}$ diet) of stock and test diets

\begin{tabular}{lc}
\hline & Test diets* $^{*}$ \\
\hline Casein† & 250 \\
Maize oilł & 50 \\
Mineral mixture $(\mathrm{Ca}$ and Fe free)§ & 27 \\
Calcium carbonatell & 75 \\
Vitamin mixtureף & 10 \\
Granulated vitamin $\mathrm{E}^{\star *}$ & 1.0 \\
Choline bitartrate & 4.0 \\
Sucrose & to make $1 \mathrm{~kg}$
\end{tabular}

* The composition of the stock diet fed during the acclimatization and recovery periods was the same as that of the test diet except for the $\mathrm{Ca}$ and $\mathrm{Fe}$ concentration. Guar-gum hydrolysate (GuarFibre; Meiji Seika Kaisha Ltd, Tokyo, Japan) and polydextrose (Litesse ${ }^{\circledR}$; Culter Food Science, Tokyo, Japan) were added to the test diet $(50 \mathrm{~g} / \mathrm{kg}$ diet). Crystallized cellulose (Avicel PH102; Asahi Chemical Industry Co. Ltd, Tokyo, Japan; $50 \mathrm{~g} / \mathrm{kg}$ diet) was added to all the test diets. Fibre sources were added to the test diets at the expense of the whole diet.

† ALACID; New Zealand Dairy Board, Wellington, New Zealand.

‡ Retinyl palmitate $(7.66 \mu \mathrm{mol} / \mathrm{kg}$ diet $)$ and ergocalciferol $(0.0504 \mu \mathrm{mol} / \mathrm{kg}$ diet) were added to the maize oil.

$\S$ The mineral mixture was prepared as established by the AIN-76 Workshop held in 1989 (Reeves, 1989), without $\mathrm{Ca}$ and Fe. It provided (mg/kg diet): P 2997, K 3746, Mg 375, I 0.32, Mn 10.0, Zn 34.7, Cu 6.00, Na 4279, Cl 6542, Se 1.05, Mo 1.00, Cr 0.50, B 0.50, V 0.25, Sn 2.00, As 1.00, Si 20.0, Ni 1.00, $\mathrm{F} 2.72$, Co 0.20 . Fe (100 mg/kg diet) was added to the stock diet fed during the acclimatization period.

I| The Ca concentration was $3.0 \mathrm{~g} / \mathrm{kg}$ diet in the test diets. For the stock diet, $\mathrm{CaCO}_{3}$ was added at $11.25 \mathrm{~g} / \mathrm{kg}$ diet $(4.5 \mathrm{~g} \mathrm{Ca} / \mathrm{kg}$ diet).

If The vitamin mixture was prepared in accordance with the AIN-76 mixture (American Institute of Nutrition, 1977) except that menadione and L-ascorbic acid were added at $5.81 \mu \mathrm{mol} / \mathrm{kg}$ (American Institute of Nutrition, 1980) and $284 \mathrm{mmol} / \mathrm{kg}$ (Harper, 1959) diet respectively.

** Vitamin E granules (Juvela; Eisai Co., Tokyo, Japan) supplied $423 \mu \mathrm{mol}$ allrac- $\alpha$-tocopheryl acetate/kg diet.
1965), and rats in the second group ( $n$ 21) were subjected to laparotomy (normal group) under anaesthesia (40 mg pentobarbital sodium/kg body weight; Abbott, North Chicago, IL, USA). In the case of gastrectomized rats, the stomach was removed after ligation of blood vessels, the cut edge of the oesophagus was end-to-side anastomosed to the upper jejunum $8 \mathrm{~cm}$ distal from the ligament of Treitz, and a $2 \mathrm{~cm}$ segment of the duodenum including the ampulla of Vater was transposed to the jejunum $5 \mathrm{~cm}$ from the position of oesophagojejunal anastomosis. After the operations, the rats were deprived of food and water for $24 \mathrm{~h}$, then were fed cows' milk for $3 \mathrm{~d}$ followed by an $\mathrm{Fe}$ free basal diet for 12-14 d. Five gastrectomized rats were killed because of surgical damage during recovery and test period.

The normal and gastrectomized rats were divided into three subgroups each using a randomized block design based on body weight after the recovery period. The rats of one subgroup were fed the Fe-free basal diet for a further $21 \mathrm{~d}$. Rats in the other two subgroups were fed the test diet containing GGH $(50 \mathrm{~g} / \mathrm{kg}$ diet; GuarFiber, Meiji Seika Kaisha, Ltd, Tokyo, Japan) and the test diet containing PD $\left(50 \mathrm{~g} / \mathrm{kg}\right.$ diet; Litesse ${ }^{\circledR}$, Culter Foods Science, Tokyo, Japan) for $21 \mathrm{~d}$ after a recovery period. GGH was prepared by partial hydrolysis with $\beta$-1,4-mannanase, having an average relative molecular mass of 15000 . PD is a random-bonded polyglucose resistant to digestive enzymes, and the average relative molecular mass of PD is 1500 . These fibre materials were added as sources of dietary fibre to the fibre-free basal diet at the expense of the whole diet (basal diet-fibre source, 95:5). Ca in the diet $(0.75 \mathrm{~mol}$ $(3.0 \mathrm{~g}) \mathrm{Ca} / \mathrm{kg}$ diet) was supplied as a water-insoluble $\mathrm{Ca}$ salt, $\mathrm{CaCO}_{3}$. The $\mathrm{Ca}$ content of the test diets was the minimum level required by normal rats of the same strain (Hara et al. 1996). Vitamin $\mathrm{B}_{12}(25.6 \mathrm{nmol} / \mathrm{kg}$ body weight per d) and $\mathrm{Fe}\left(32.2 \mu \mathrm{mol} / \mathrm{kg}\right.$ body weight per d) as $\mathrm{FeCl}_{2}$ (Wako Pure Chemical Industries, Tokyo, Japan) were supplied subcutaneously every $5 \mathrm{~d}$ during the recovery and test periods. Body weight and food intakes were measured every day.

Faeces were collected continuously for the last $3 \mathrm{~d}$ during feeding of the test diets to evaluate $\mathrm{Ca}$ excretion and apparent absorption of $\mathrm{Ca}$. The faeces excreted in the $3 \mathrm{~d}$ period were sampled and freeze-dried.

At the end of the experiment, the rats were killed under pentobarbital anaesthesia. The right femur and the caecum were removed. The femur was freeze-dried and weighed. The caecum was removed without loss of its contents, the contents were collected, frozen immediately with liquid $\mathrm{N}$, and stored at $-40^{\circ} \mathrm{C}$ until subsequent analyses. The caecal wall was washed with saline and weighed. The weight of the contents was evaluated by the difference between the weight of the caecum with and without its contents.

\section{In vitro calcium absorption in everted sacs of the small intestine (Experiment 2)}

Male Sprague-Dawley rats, weighing about $100 \mathrm{~g}$, were given free access to tap water and the semi-purified stock diet shown in Table 1 for an acclimatization period of more than $7 \mathrm{~d}$ and were then starved for $24 \mathrm{~h}$. 
To prepare everted sacs, the rats were anaesthetized with sodium pentobarbital and killed. Immediately, three consecutive segments of $3 \mathrm{~cm}$ each were dissected from the upper (jejunum) and lower (ileum) half of the small intestine. The intestinal segments were everted with a plastic rod and ligated with surgical silk at one end. An artificial serosal fluid $(0.8 \mathrm{ml})$ was instilled from the other end, which was then ligated. The serosal fluid was $30 \mathrm{~mm}-$ Tris- $\mathrm{HCl}$ buffer, $\mathrm{pH} \mathrm{7.4,} \mathrm{containing} 125 \mathrm{mM}-\mathrm{NaCl}, 4 \mathrm{mM}-$ $\mathrm{KCl}, 10 \mathrm{mM}$-glucose and $1.25 \mathrm{mM}-\mathrm{CaCl}_{2}$, saturated with a mixed gas $\left(\mathrm{O}_{2}-\mathrm{CO}_{2}(95: 5, \mathrm{v} / \mathrm{v})\right)$ and warmed to $37^{\circ} \mathrm{C}$. The sacs were transferred to individual flasks containing $30 \mathrm{ml}$ gassed $\left(\mathrm{O}_{2}-\mathrm{CO}_{2}(95: 5, \mathrm{v} / \mathrm{v})\right)$ and warmed artificial mucosal fluid (30 mM-Tris-HCl buffer, $\mathrm{pH} 7.4$, containing $125 \mathrm{mM}-\mathrm{NaCl}, 4 \mathrm{mM}-\mathrm{KCl}, 10 \mathrm{mM}$-glucose and $10 \mathrm{mM}-$ $\mathrm{CaCl}_{2}$ ). PD and GGH were added to the mucosal fluid up to $50 \mathrm{~g} / \mathrm{l}$. Sacs were incubated for $30 \mathrm{~min}$ in a water bath at $37^{\circ} \mathrm{C}$ shaken at 110 r.p.m. We observed linear increases in $\mathrm{Ca}$ absorption by the gut sacs for 30 min (data not shown). After collection of the serosal fluid, length of sacs between both ligations were measured to calculate $\mathrm{Ca}$ absorption rate by the sacs.

\section{Analytical methods}

Freeze-dried faeces were milled to very fine powder. The powdered faeces (about $70 \mathrm{mg}$ ) and dried right femur were carefully wet-ashed in a mixture of $10 \mathrm{M}-\mathrm{HNO}_{3}$ and $2.3 \mathrm{M}-$ $\mathrm{HClO}_{4}$ without drying up. The caecal contents diluted with nine volumes deionized water were homogenized by means of a Teflon homogenizer. Amounts of total $\mathrm{Ca}$ in the homogenates were measured after the samples had been wet-ashed in the same way as for the faeces. Soluble $\mathrm{Ca}$ was assayed in the supernatant obtained upon centrifugation (30 $000 \mathrm{~g}$ for $20 \mathrm{~min}$ ) of the homogenate. Ca concentrations in the ashed solutions were measured by atomic absorption spectrophotometry (AA-6400F; Shimadzu Corporation, Kyoto, Japan) after adequate dilution with water after addition of strontium chloride solution (final concentration $57 \mathrm{mmol} / \mathrm{l}$ ). Although we assayed a relatively small sample of dried faeces $(70 \mathrm{mg})$, the CV of the measurement was $3.4 \%$. Recovery of $\mathrm{Ca}$ in the diet was 97.3 (SE 0.7) \%. The Ca concentration of the artificial serosal fluid in the everted sac was measured by a commercial kit (Calcium-C test; Wako Pure Chemical Industries, Osaka, Japan).

Concentrations of short-chain fatty acids (acetic, propionic and butyric acids) in the homogenate of the caecal contents were evaluated by a method described previously (Hara et al. 1994). Individual short-chain fatty acids were measured by GLC (Shimadzu GC-14A, with a prepacked glass column $\left(1600 \mathrm{~mm} \times 3 \mathrm{~mm}, \quad \mathrm{SP}-1220+\mathrm{H}_{3} \mathrm{PO}_{4}\right.$ $(15 \%+1 \%$ respectively) on $80-100$ mesh Chromosorb W-AW DMCS; Shimadzu Corporation) after adding phosphoric acid (final concentration $0.67 \mathrm{~mol} / \mathrm{l}$ ).

\section{Calculations and statistical analysis}

The apparent absorption of $\mathrm{Ca}$ was calculated as follows: apparent $\mathrm{Ca}$ absorption $(\%)=100 \times($ total $\mathrm{Ca}$ intake faecal $\mathrm{Ca}$ excretion)/total $\mathrm{Ca}$ intake.
The rate of $\mathrm{Ca}$ absorption by the everted sacs was expressed as the net increase in the amount of $\mathrm{Ca}$ in the artificial serosal fluid per $\mathrm{cm}$ intestinal segment per $\mathrm{h}$.

The results were analysed by two-way ANOVA (Gastrectomy $\times$ Dietary fibre) in Experiment 1 and oneway ANOVA in Experiment 2. Duncan's multiple range test was used to determine whether mean values were significantly different (Duncan, 1995; $P<0.05$ ). These statistical analyses were done by the GLM procedure of the Statistical Analysis System program (version 6.07, SAS Institute Inc., Cary, NC, USA).

\section{Results}

Apparent calcium absorption in normal and gastrectomized rats (Experiment 1)

Food intakes were similar in all groups (Table 2), however, body-weight gains were lower in each diet group in gastrectomized rats than the corresponding diet group in normal rats. In the gastrectomized rats, the mean value for the PD group was higher than that of the basal-diet group. Faecal dry weight excreted for the last $3 \mathrm{~d}$ was higher in gastrectomized rats fed PD than in rats of the other groups.

Apparent $\mathrm{Ca}$ absorption for the last $3 \mathrm{~d}$ of the test period was strikingly lower in the gastrectomized rats than in the normal rats fed the basal diet, and the reduced absorption caused by gastrectomy was doubled in rats fed GGH and PD. The Ca absorption of the PD group was higher than those of the other two groups in the normal rats (Fig. 1).

Femur dry weights and Ca concentrations in the femurs were lower in the all gastrectomized groups than in the normal groups (Fig. 2). Femur $\mathrm{Ca}$ concentrations were higher in the PD group than in the basal and GGH group for the normal and gastrectomized rats respectively.

Total $\mathrm{Ca}$ pool in the caecal contents was much higher,

Table 2. Body-weight gain $(\mathrm{g} / \mathrm{d})$ and food intake $(\mathrm{g} / \mathrm{d})$ during feeding of test diets for $21 \mathrm{~d}$ and faecal dry weight $(\mathrm{g} / 3 \mathrm{~d})$ for the last $3 \mathrm{~d}$ in the test period of normal (laparotomized) and gastrectomized rats fed diets with and without addition of guar-gum hydrolysate (GGH) or polydextrose $(50 \mathrm{~g} / \mathrm{kg} \text { diet })^{*}$

(Mean values with their standard errors)

\begin{tabular}{|c|c|c|c|c|c|c|c|}
\hline \multirow[b]{2}{*}{ Diet } & \multirow[b]{2}{*}{$n$} & \multicolumn{2}{|c|}{$\begin{array}{l}\text { Body weight } \\
\text { gain }\end{array}$} & \multicolumn{2}{|c|}{ Food intake } & \multicolumn{2}{|c|}{$\begin{array}{l}\text { Faecal dry } \\
\text { weight }\end{array}$} \\
\hline & & Mean & SE & Mean & SE & Mean & SE \\
\hline \multicolumn{8}{|l|}{ Normal } \\
\hline Basal & 7 & $2.48^{\mathrm{ab}}$ & 0.090 & $10 \cdot 6$ & 0.01 & $2 \cdot 13^{\mathrm{b}}$ & 0.058 \\
\hline $\mathrm{GGH}$ & 7 & $2 \cdot 66^{\mathrm{ab}}$ & 0.054 & $10 \cdot 6$ & 0.02 & $2 \cdot 32^{\mathrm{b}}$ & 0.060 \\
\hline Polydextrose & 7 & $2 \cdot 77^{\mathrm{a}}$ & 0.107 & $10 \cdot 6$ & 0.01 & $2 \cdot 29^{\mathrm{b}}$ & 0.107 \\
\hline \multicolumn{8}{|l|}{ Gastrectomized } \\
\hline Basal & 7 & $1.90^{\mathrm{d}}$ & 0.118 & $11 \cdot 0$ & 0.51 & $2 \cdot 42^{\mathrm{b}}$ & 0.137 \\
\hline $\mathrm{GGH}$ & 8 & $2 \cdot 22^{\mathrm{cd}}$ & 0.146 & $10 \cdot 3$ & 0.52 & $2 \cdot 36^{\mathrm{b}}$ & 0.192 \\
\hline Polydextrose & 7 & $2 \cdot 42^{\mathrm{bc}}$ & 0.211 & $11 \cdot 0$ & 0.46 & $2 \cdot 97^{\mathrm{a}}$ & 0.174 \\
\hline \multicolumn{8}{|c|}{ Statistical significance (ANOVA) of effect of: } \\
\hline Gastrectomy (GX) & & $P=0$ & 017 & $\mathrm{~N}$ & & \multirow{3}{*}{\multicolumn{2}{|c|}{$\begin{array}{c}P=0.002 \\
P=0.018 \\
\text { NS }\end{array}$}} \\
\hline Dietary fibre (DF) & & $P<0$ & 0.001 & $\mathrm{~N}$ & & & \\
\hline $\mathrm{GX} \times \mathrm{DF}$ & & $\mathrm{N}$ & & $\mathrm{N}$ & & & \\
\hline
\end{tabular}




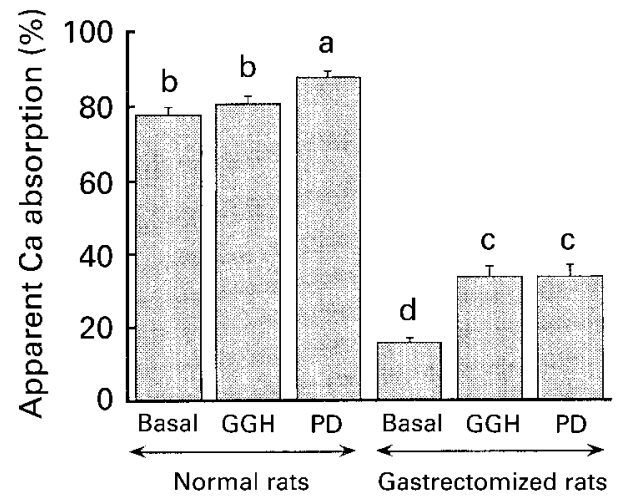

Fig. 1. Apparent calcium absorption in normal and gastrectomized rats fed basal diet $(\mathrm{Ba})$ or a guar-gum hydrolysate $(\mathrm{GGH})$ - or polydextrose (PD)-containing diet (soluble fibre sources, $50 \mathrm{~g} / \mathrm{kg}$ diet) $21 \mathrm{~d}$ after the start of feeding the test diets in Experiment 1. For details of diets and procedures, see Table 1 and p. 656. Values are means with their standard errors for seven rats except for GGH-fed gastrectomized group (eight rats). $P$ values estimated by two-way ANOVA were $<0.001$ for Gastrectomy (GX) and Dietary fibre (DF), and 0.002 for $G X \times D F{ }^{a, b, c, d}$ Mean values with unlike superscript letters were significantly different between groups $(P<0.05)$.

and soluble Ca was much lower in the gastrectomized rats than in the normal rats (Table 3). Feeding GGH and PD did not influence the soluble $\mathrm{Ca}$ concentration of the caecal contents in the normal rats. In gastrectomized rats the concentration in the GGH group was significantly higher than those gastrectomized rats fed the basal or PD diet $(P=0.005)$.

The weights of the caecal walls and the caecal contents were greater and $\mathrm{pH}$ of the contents was lower in both fibre-fed groups than in the basal-diet group in the normal and gastrectomized rats (Table 4). Within the fibre-fed groups, $\mathrm{pH}$ in the $\mathrm{PD}$ group was lower than that in the GGH group in normal and gastrectomized rats.

Concentration of acetic, propionic and butyric acids in the caecal contents are shown in Table 5. In normal and gastrectomized rats fed PD, these major short-chain fatty acid concentrations were clearly lower than those in rats fed basal and GGH-containing diets except for butyrate in normal rats.

\section{Calcium absorption by everted sacs of the small intestine} (Experiment 2)

In vitro $\mathrm{Ca}$ absorption by everted sacs of the ileum was significantly increased $(P<0.05)$ by addition of PD to the mucosal fluid, but not by addition of GGH compared with the absorption from the no-fibre fluid (Fig. 3). The Ca absorption of the jejunal sacs changed by addition of both fibres similarly to those of the ileal sacs, but the changes were not significantly different.

\section{Discussion}

Body-weight gains in gastrectomized rats were lower than those in normal rats in spite of the fact that food intakes were similar between both rats. Faecal outputs were not significantly increased by gastrectomy except for rats fed PD. The results suggest that some metabolic changes, rather than impaired nutrient absorption, is involved in the growth retardation in the gastrectomized rats.

In the present study, we examined the effects of a less
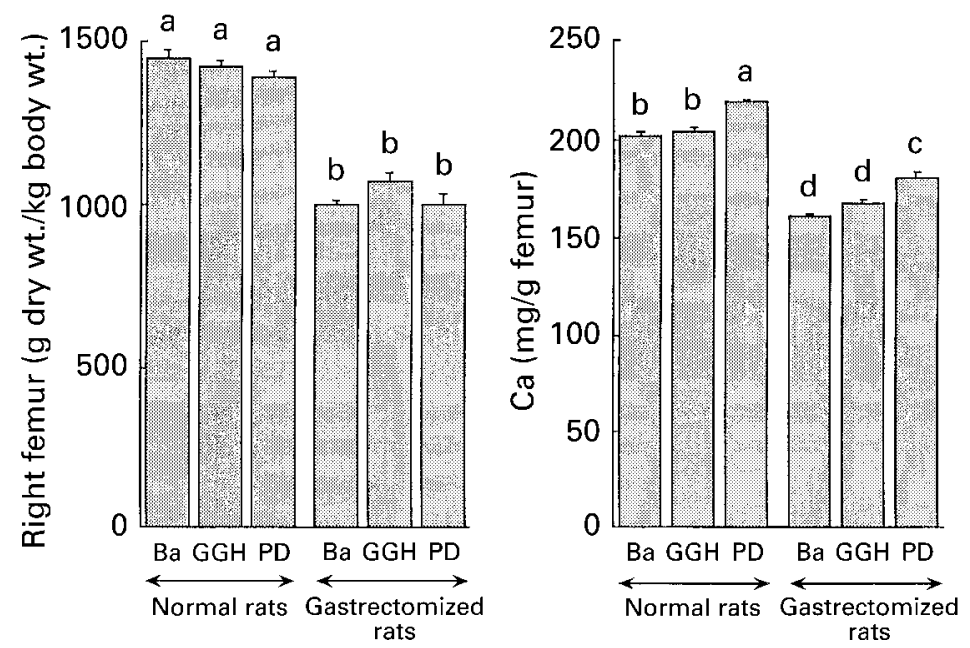

Fig. 2. Femur dry weight and calcium concentration in the femur in normal and gastrectomized rats fed basal diet $(\mathrm{Ba})$, or a guar-gum hydrolysate $(\mathrm{GGH})$ - or polydextrose (PD)-containing diet (soluble fibre sources, $50 \mathrm{~g} / \mathrm{kg}$ diet) $21 \mathrm{~d}$ after the start of feeding the test diets in Experiment 1. For details of diets and procedures, see Table 1 and p. 656. Values are means with their standard errors for seven rats except for GGH-fed gastectomized group (eight rats). $P$ values estimated by two-way ANOVA for femur dry weight were $<0.001$ for Gastrectomy (GX), NS for Dietary fibre (DF), and NS for $\mathrm{GX} \times \mathrm{DF}$; for calcium concentration the $P$ values were $<0.001$ for Gastrectomy $(G X)$ and Dietary fibre (DF), and NS for GX $\times$ DF, (NS, $P \geq 0.05)$. ${ }^{a, b, c, d}$ Mean values with unlike superscript letters were significantly different between groups $(P<0.05)$. 
(A)

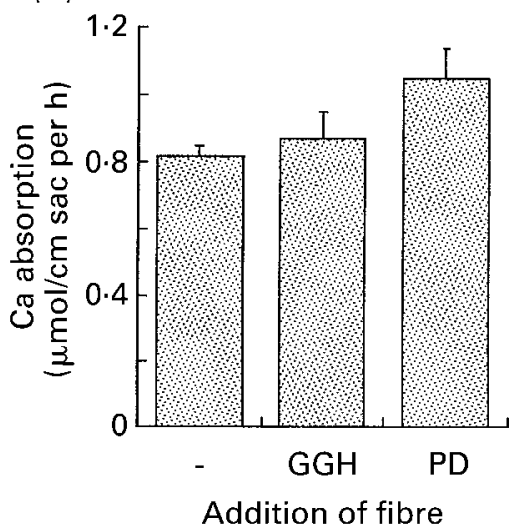

(B)

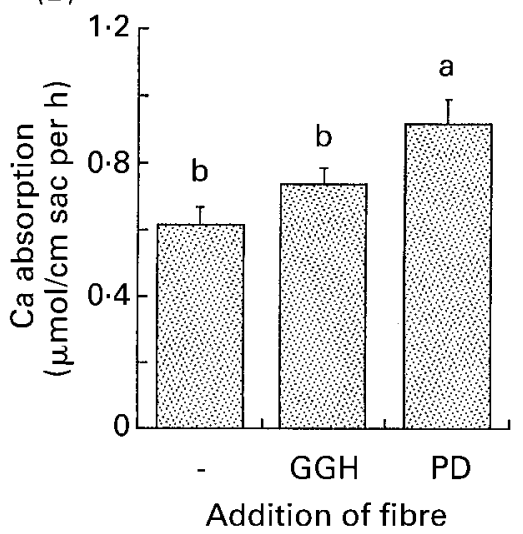

Fig. 3. Calcium absorption by everted jejunal (A) and ileal (B) sacs of acclimatized rats fed on the stock diet for more than $7 \mathrm{~d}$ in Experiment 2. Guar-gum hydrolysate (GGH) and polydextrose (PD) were added to mucosal medium $(50 \mathrm{~g} / \mathrm{l})$. For details of diets and procedures, see Table 1 and p. 656. Values are means with their standard errors for five rats per group. $P$ values estimated by one-way ANOVA were NS and 0.011 for jejunal and ileal sac respectively. ${ }^{\mathrm{a}, \mathrm{b}}$ Mean values with unlike superscript letters were significantly different between groups $(P<0.05)$.

Table 5. Concentrations of short-chain fatty acids $(\mu \mathrm{mol} / \mathrm{g}$ wet caecal contents) of normal (laparotomized) and gastrectomized rats fed diets with and without addition of guar-gum hydrolysate (GGH) or polydextrose (50 g/kg diet) for $21 \mathrm{~d}^{*}$

(Mean values with their standard errors)

\begin{tabular}{|c|c|c|c|c|c|c|c|}
\hline \multirow[b]{2}{*}{ Diet } & \multicolumn{3}{|c|}{ Acetic acid } & \multicolumn{2}{|c|}{ Propionic acid } & \multicolumn{2}{|c|}{ Butyric acid } \\
\hline & $n$ & Mean & SE & Mean & SE & Mean & SE \\
\hline \multicolumn{8}{|l|}{ Normal } \\
\hline Basal & 7 & $54 \cdot 1^{\mathrm{ab}}$ & 4.65 & $22 \cdot 4^{\mathrm{b}}$ & 1.55 & $11 \cdot 5^{\mathrm{a}}$ & 0.78 \\
\hline GGH & 7 & $42 \cdot 8^{\mathrm{bc}}$ & $2 \cdot 16$ & $25 \cdot 8^{\mathrm{b}}$ & 1.32 & $4 \cdot 35^{\mathrm{b}}$ & 0.639 \\
\hline Polydextrose & 7 & $21 \cdot 1^{\mathrm{d}}$ & $2 \cdot 04$ & $12 \cdot 0^{c}$ & 0.90 & $2 \cdot 51^{b}$ & 0.522 \\
\hline \multicolumn{8}{|l|}{ Gastrectomized } \\
\hline Basal & 7 & $61 \cdot 8^{\mathrm{a}}$ & 5.72 & $22 \cdot 7^{b}$ & 3.54 & $14 \cdot 0^{\mathrm{a}}$ & $1 \cdot 12$ \\
\hline GGH & 8 & $74 \cdot 1^{\mathrm{ab}}$ & 9.66 & $50 \cdot 8^{\mathrm{a}}$ & 7.09 & $7 \cdot 83^{\mathrm{a}}$ & 3.03 \\
\hline Polydextrose & 7 & $29 \cdot 3^{\mathrm{cd}}$ & 2.69 & $19 \cdot 9^{b}$ & 0.89 & $3.94^{b}$ & 0.602 \\
\hline \multicolumn{8}{|c|}{ Statistical significance (ANOVA) of effect of: } \\
\hline \multirow{2}{*}{\multicolumn{2}{|c|}{ Gastrectomy (GX) }} & \multicolumn{2}{|c|}{$P=0.010$} & \multicolumn{2}{|c|}{$P=0.003$} & \multirow{2}{*}{\multicolumn{2}{|c|}{$\begin{array}{l}P=0.009 \\
P<0.001\end{array}$}} \\
\hline & & $P<0$ & .001 & $P<0$ & 001 & & \\
\hline \multicolumn{2}{|l|}{$\mathrm{GX} \times \mathrm{DF}$} & \multicolumn{2}{|c|}{ NS } & \multicolumn{2}{|c|}{$P=0.019$} & \multicolumn{2}{|c|}{ NS } \\
\hline
\end{tabular}

${ }^{a, b, c, d}$ Mean values within a column with unlike superscript letters were significantly different $(P<0.05$; NS $P \geq 0.05$; Duncan's multiple range test).

* For details of diets and procedures, see Table 1 and p. 656

propionic acid concentration in the PD group was lower even than in the basal group in normal and gastrectomized rats. Acetic acid concentration in the PD-fed groups was also lower than that for the other two diet groups in normal and gastrectomized rats. These results suggest that caecal fermentation is not greatly involved in the increase of $\mathrm{Ca}$ absorption on feeding PD. We did not observe the fermentation in the colon; however, dietary fibre is mainly fermented in the caecum in rats.

As described earlier, we did not find any contribution of the caecum to the increase of $\mathrm{Ca}$ absorption after feeding PD in normal and gastrectomized rats. We showed that PD, but not GGH, enhanced $\mathrm{Ca}$ absorption of the ileal segment in Experiment 2 (Fig. 3). From these results, we speculate that the small intestine largely contributes to the enhancement of $\mathrm{Ca}$ absorption by feeding PD in normal and gastrectomized rats. Feeding of GGH may increase $\mathrm{Ca}$ absorption in the large intestine in the gastrectomized rats by increasing fermentation products.

In conclusion, $\mathrm{PD}$ feeding increased $\mathrm{Ca}$ absorption and bone mineralization in normal and gastrectomized rats. Small intestinal absorption may be involved in these beneficial effects of PD. The PD feeding improved bone mineralization impaired by gastrectomy. Ingestion of PD also increased bone $\mathrm{Ca}$ concentration in normal rats, which may be relevant for decreasing the risk of osteoporosis.

\section{References}

Achour L, Fourie B, Briet F, Pellier P, Marteau P \& Rambaud JC (1994) Gastrointestinal effects and energy value of polydextrose in healthy nonobese men. American Journal of Clinical Nutrition 59, 1362-1368.

American Institute of Nutrition (1977) Report of the American Institute of Nutrition ad hoc committee on standards for nutritional studies. Journal of Nutrition 107, 1340-1348.

American Institute of Nutrition (1980) Second report of the ad hoc committee on standards for nutritional studies. Journal of Nutrition 110, 1726.

Armbrecht HJ \& Wasserman RH (1976) Enhancement of $\mathrm{Ca}^{++}$ uptake by lactose in the rat small intestine. Journal of Nutrition 106, 1265-1271.

Bamba T, Fuse K, Chun W \& Hosoda S (1993) Polydextrose and activities of brush-border membrane enzymes of small intestine in rats and glucose absorption in humans. Nutrition 9, 233-236.

Duncan DB (1995) Multiple range and multiple $F$ tests. Biometrics 11, 1-42.

Goda T, Takase S \& Hosoya N (1993) Maltitol-induced increase of transepithelial transport of calcium in rat small intestine. Journal of Nutritional Science and Vitaminology 39, 589-595.

Hara H, Nagata M, Ohta A \& Kasai T (1996) Increases in calcium absorption with ingestion of soluble dietary fibre, guar-gum 
hydrolysate, depend on the caecum in partially nephrectomized and normal rats. British Journal of Nutrition 76, 773-784.

Hara H, Saito Y, Nakashima H \& Kiriyama S (1994) Evaluation of fermentability of acid-treated maize husk by rat caecal bacteria in vivo and in vitro. British Journal of Nutrition $\mathbf{7 1}$, 719-729.

Hara H, Suzuki T, Kasai T, Aoyama Y \& Ohta A (1999) Ingestion of guar-gum hydrolysate partially restores calcium absorption in the large intestine lowered by suppression of gastric acid secretion in rats. British Journal of Nutrition 81, 315-321.

Harper AE (1959) Amino acid balance and imbalance. 1. Dietary level of protein and amino acid imbalance. Journal of Nutrition 68, 405-418.

Juhr NC \& Franke J (1992) A method for estimating the available energy of incompletely digested carbohydrates in rats. Journal of Nutrition 122, 1425-1433.

Karbach U \& Feldmeier H (1993) The cecum is the site with the highest calcium absorption in rat intestine. Digestive Diseases and Sciences 38, 1815-1824.

Koga S, Nishimura O, Iwai N, Kishi K, Takeuchi T, Hinohara T \& Okamoto T (1979) Clinical evaluation of long-term survival after total gastrectomy. Americal Journal of Surgery 138, 635639.

Lambert R (1965) Gastrectomy in the rat. In Surgery of the Digestive System in Rats, English version, pp. 327-365. Springfield, IL: Charles C Thomas.

Nilas L, Christiansen C \& Christiansen J (1985) Regulation of vitamin D and calcium metabolism after gastrectomy. Gut 26, 252-257.

Ogata S, Fujimoto K, Iwakiri R, Matsunaga C, Ogawa Y, Koyama T \& Sakai T (1997) Effect of polydextrose on absorption of triglyceride and cholesterol in mesenteric lymph-fistula rats. Proceedings of the Society for Experimental Biology \& Medicine 215, 53-58.

Ohta A, Baba S, Ohtsuki M, Takizawa T, Adachi T \& Hara H (1997) In vivo absorption of calcium carbonate and magnesium oxide from the large intestine in rats. Journal of Nutritional Science and Vitaminology 43, 35-46.

Ohta A, Ohtsuki M, Hosono A, Adachi T, Hara H \& Sataka T (1998) Dietary fructooligosaccharides prevent osteopenia after gastrectomy in rats. Journal of Nutrition 128, 106-110.

Reeves PG (1989) AIN-76 diet, should we change the formulation? Journal of Nutrition 119, 1081-1082.

Suzuki T, Hara H, Kasai T \& Tomita F (1998) Effects of difructose anhydride III on calcium absorption in small and large intestines of rats. Bioscience Biotechnology and Biochemistry 62, 837-841.

Takahashi H, Yang SI, Kim M \& Yamamoto T (1994) Protein and energy utilization of growing rats fed on the diets containing intact or partially hydrolyzed guar gum. Comparative Biochemistry and Physiology 107A, 255-260.

Trinidad TP, Wolever TM \& Thompson LU (1996) Effect of acetate and propionate on calcium absorption from the rectum and distal colon of humans. American Journal of Clinical Nutrition 63, 574-578.

Yoshioka M, Shimomura Y \& Suzuki M (1994) Dietary polydextrose affects the large intestine in rats. Journal of Nutrition 124, 539-547.

Younes H, Demigné C, Rémésy C \& (1996) Acidic fermentation in the caecum increases absorption of calcium and magnesium in the large intestine of the rat. British Journal of Nutrition 75, 301-314. 